\title{
WORK ENGAGEMENT, BURNOUT AND RELATED CONSTRUCTS AS PREDICTORS OF TURNOVER INTENTIONS
}

Authors:

Janine du Plooy

Gert Roodt ${ }^{1}$

\section{Affiliations:}

${ }^{1}$ Department of Industrial

Psychology and People

Management, University of

Johannesburg, South Africa

\section{Correspondence to:}

Gert Roodt

email:

groodt@uj.ac.za

Postal address:

Department of Industrial Psychology and People

Management, University of Johannesburg, PO Box 524,

Auckland Park 2006, South Africa

\section{Keywords:}

work engagement; burnout; organisational citizenship behaviour (OCB); alienation; turnover intention; survey research

\section{Dates:}

Received: 26 July 2010

Accepted: 11 Nov. 2010

Published: 08 Dec. 2010

How to cite this article: Du Plooy, J., \& Roodt, G. (2010). Work engagement, burnout and related constructs as predictors of turnover intentions. SA Journal of Industrial Psychology/SA Tydskrif vir Bedryfsielkunde, 36(1), Art. \#910, 13 pages. DOI: 10.4102/ sajip.v36i1.910

\section{This article is available} at: http://www.sajip.co.za

\section{Note:}

The research reported in this article is the product of a collaborative research project between the University of Johannesburg and the Vrije University, Amsterdam. Financial support from SANPAD for conducting this research is hereby acknowledged. Conclusions drawn or opinions expressed in this article are those of the author and do not necessarily reflect the views of SANPAD.

\section{ABSTRACT}

Orientation: The focus of the study was to investigate the predictive relationship between the work engagement-burnout continuum and turnover intentions.

Research purpose: The main purpose of the study was to determine whether work engagement, burnout, organisational citizenship behaviour (OCB) and work alienation are predictors of turnover intentions.

Motivation for the study: Organisations operating within the 21st century face significant challenges in the management of talent and human capital. One in particular is voluntary employee turnover and the lack of appropriate business models to track this process.

Research design, approach and method: A secondary data analysis (SDA) was performed in a quantitative research tradition on the cross-sectional survey data collected from a large South African Information and Communication Technologies (ICT) sector company $(n=2429)$.

Main findings: The results of the study confirmed the predictive model (work engagement, burnout, $\mathrm{OCB}$ and work alienation) of turnover intention. Specifically, work engagement and OCBs were significantly negatively related to turnover intention; whilst burnout and work alienation were significantly positively related to turnover intention. Several third-variable relationships, such as biographic and demographic variables, indicated statistical significance.

Practical/managerial implications: Practical implications of the study could impact on human resource (HR) value-chain activities in the form of evidence-based and improved recruitment and selection procedures, employee retention strategies and training and development interventions. Issues concerning talent management could also be addressed.

Contribution/value-add: The study described in this article took Industrial/Organisational (I/O) psychological concepts and linked them in unique combinations to establish better predictive validity of a new turnover intentions model.

\section{INTRODUCTION}

Studies that report results on reasons why employees choose to leave or stay with a particular organisation (Dreher \& Dougherty, 1980; Griffeth, Hom, \& Gaertner, 2000; Kotzé \& Roodt, 2005; Lee, Mitchell, Holtom, McDaniel, \& Hill, 1999; Roodt \& Bothma, 1997) are gaining importance and most of them focus on a set of negative consequences that are associated with employee turnover (Bluedorn, 1982; Mobley, 1982). As a result, employee turnover and its associated expenses for organisations are a key challenge (Bluedorn, 1982).

The study contributes theoretically to the body of knowledge on turnover and possible interventions to deter employee turnover (retention strategies). Altogether, the management of employee turnover statistics and its associated costs could be improved with an increased understanding of the turnover process.

The work engagement-burnout continuum has recently started receiving a lot of research attention (Maslach, Schaufeli, \& Leiter, 2001; Schaufeli \& Bakker, 2003; Schutte, Toppinen, Kalimo, \& Schaufeli, 2000) that has delivered contradicting results. One viewpoint constitutes the core constructs of work engagement and burnout as opposite poles of two continua (vigour-exhaustion and dedication-cynicism) labelled energy and identification respectively (González-Romá, Schaufeli, Bakker, \& Lloret, 2006). Work engagement is 'characterized by a high level of energy and strong identification with one's work', whilst burnout is 'characterized by the opposite: a low level of energy combined with poor identification with one's work' (Schaufeli \& Bakker, 2003, p. 5; Bakker, Schaufeli, Leiter, \& Taris, 2008). Therefore, work engagement and burnout could be recognised as inseparable and co-dependent constructs that share more or less $10-25 \%$ of their variance and are moderately negatively related (Schaufeli \& Bakker, 2004; Schaufeli, Salanova, González-Romá, \& Bakker, 2002). The link between work engagement, burnout and turnover intentions is empirically well established (Schaufeli \& Bakker, 2004).

The second viewpoint constitutes work engagement and burnout as strongly related, but fundamentally different in their separation in the work experience and are, therefore, not opposite poles of a continuum (Denton, Newton, \& Bower, 2008; Huhtala \& Parzefall, 2007; Rothmann \& Joubert, 2007; Schaufeli \& Bakker, 2004; Schaufeli et al., 2002). Work engagement is defined as a 'positive, fulfilling, work-related state of mind that is characterised by vigour, dedication, and absorption' (Schaufeli \& Bakker, 2004, p. 
295). Burnout, on the other hand, is defined by Maslach and Jackson (1981, pp. 99) as a 'syndrome of emotional exhaustion and cynicism that occurs frequently amongst individuals who do 'people-work' of some kind'.

However, Industrial/Organisational (I/O) psychological literature fails to provide any substantial links between the combination of work engagement, burnout, organisational citizenship behaviour (OCB), work alienation and turnover intentions. This indicates an absence of research in this regard. Turnover intention is defined as 'a conscious and deliberate willfulness to leave the organization' (Tett \& Meyer, 1993, p. 262). Work behaviours and attitudes such as OCB and work alienation can be theoretically linked to withdrawal behaviours and the turnover process (cf Ravichandran \& Gilmore, 2007; Shepard, 1972 respectively) and the position work engagement and burnout hold in the sequence leading up to turnover could help define the turnover process more comprehensively.

OCB is also known as extra-role performance (Organ, \& Paine, 1999; Podsakoff, MacKenzie, \& Bommer, 1996) and is defined as 'individual behavior that is discretionary, not directly or explicitly recognized by the formal reward system, and that in the aggregate promotes the effective functioning of the organization' (Organ 1988, p. 4). Furthermore, work alienation is defined as a 'state of psychological separation from work insofar as work is perceived to lack the potentiality for satisfying one's salient needs and expectations' (Kanungo, 1979, p. 131). A more complete understanding of turnover intentions should secure solutions to more effectively manage employee turnover.

The research question can therefore be formulated as: Are the work engagement, burnout, OCB and work alienation constructs significantly related to (and predictors of) turnover intentions? Consequently, the main objective of the research is to determine whether different constructs such as work engagement, burnout, OCB and work alienation are related to (and predictors of) turnover intentions.

\section{A REVIEW OF THE LITERATURE}

This study conceptualised a continuum with poles of extremity that is work engagement and burnout and further considered other constructs relating to organisational behaviours and attitudes and their respective relationships to turnover intentions. The mentioned constructs were conceptually grouped together to create a more holistic model that relates to turnover intentions. The research model is embedded in an existing theoretical framework called the Job Demands-Resources (JD-R) model and helps to map these organisational attitudes and their relationships with turnover intentions. A brief discussion on the interrelatedness of the JD-R model will now follow, pursued by an in depth discussion on work engagement and burnout, an introduction to the construct turnover intention and relevant findings obtained surrounding other related constructs of work engagement and burnout.

The JD-R model will be briefly discussed here to create a context for understanding work engagement and burnout. The JD-R model was extended by including work engagement, health impairment and organisational withdrawal in the Comprehensive Burnout and Engagement (COBE) model (Jackson, Rothmann, \& van der Vijver, 2006; Schaufeli \& Bakker, 2004). The COBE model can be applied in explaining the consequences of work engagement and burnout in relation to turnover intentions (Bakker, Demerouti, \& Schaufeli, 2003; Demerouti, Bakker, Nachreiner, \& Schaufeli, 2001; Schaufeli \& Bakker, 2004).

The broad JD-R model suggests that every occupation has exclusive job characteristics that can be divided into two categories, that is, job demands and job resources (Demerouti

\section{et al., 2001):}

Job demands refer to those physical, social, or organizational aspects of the job that require sustained physical or mental effort and are therefore associated with certain physiological and psychological costs (e.g., exhaustion).

(Demerouti et al., 2001, p. 501)

Exhaustion may then snowball into job stress (Demerouti et al., 2001) and negative psychological states such as burnout (Schaufeli \& Bakker, 2004). Schaufeli and Buunk (2003) went a step further and described burnout as a type of job stress that influences the work-related emotional well-being of employees.

\section{Job resources, on the other hand,}

refer to those physical, psychological, social, or organizational aspects of the job that may do any of the following: (a) be functional in achieving work goals; (b) reduce job demands and the associated physiological and psychological costs; and (c) stimulate personal growth and development.

(Demerouti et al., 2001, p. 501)

External resources are divided into three levels, namely organisational (career opportunities), social (support from colleagues) and task (performance feedback) (Demerouti et al., 2001). In short, job engagement was found to mediate the relationship between available job resources and turnover intentions (Schaufeli \& Bakker, 2004). Demerouti et al. (2001) further suggest that a shortage of available resources will affect the degree of job demands fulfilment, which will facilitate withdrawal behaviour. On a long-term scale, withdrawal behaviours can lead to work disengagement (Demerouti et al., 2001).

The JD-R model depicts job resources as the sole predictor of work engagement (Bakker et al., 2003). Specific job resources, such as social support by colleagues, supervisory coaching, performance feedback and time control have a significant inverse relation to turnover intentions and organisational involvement (commitment) mediates this causal relationship (Bakker et al., 2003). According to the JD-R model's effort to explain burnout, job demands predict feelings of exhaustion and lacking job resources predict work disengagement (Demerouti et al., 2001). Job demands, such as work overload, changes in the task and emotional demands were found to predict exhaustion (Bakker et al., 2003). In this regard, burnout is researched by focusing on exhaustion which has been shown to be the main indicator of the burnout syndrome (Lee \& Ashforth, 1993; Maslach \& Jackson, 1981). Against this background, the constructs work engagement and burnout will be discussed in more depth.

It should be noted that various researchers have argued for the significance in differentiating between the types of engagement, because they differ in their respective antecedents and consequences (Saks, 2006; Simpson, 2008). According to reviewed literature, six types of work-related engagement were identified:

- job engagement

- organisation engagement (Saks, 2006)

- personal engagement,

- burnout/engagement

- work engagement

- employee engagement.

(Simpson, 2008)

The focus of the current study has been specifically maintained on work engagement and its consequential relations.

It has been reported that employee engagement is likely to be connected to employees' attitudes, intentions and behaviours (Saks, 2006) and that work engagement shows potential to constructively contribute to the employing organisations of the engaged employees (Koyuncu, Burke, \& Fiksenbaum, 2006). Thus, it comes as no surprise that work engagement has been 
linked to a decline in intentions to quit (Koyuncu et al., 2006; Saks, 2006; Schaufeli \& Bakker, 2004). The JD-R model depicts job resources as the sole predictor of work engagement and engagement as the mediator ${ }^{1}$ between job resources and turnover intentions (Bakker et al., 2003) and, finally, work engagement is shown to be directly related to turnover intentions (Schaufeli \& Bakker, 2004). The findings of Hakanen, Bakker and Schaufeli (2006) suggest that a lack of job resources to meet job demands may be linked to burnout, which may lead to decreased work engagement. According to the literature (Schaufeli \& Bakker, 2004), decreased work engagement could in turn lead to increased turnover intentions.

The three subcomponents of burnout are emotional exhaustion, depersonalisation and diminished personal accomplishment (Maslach \& Jackson, 1981). Burnout has been found to contribute to the intent of employees to leave their organisations and it has been well documented by two Australian studies (Lingard, 2003; Sims, 2007); the latter study suggested cynicism and emotional exhaustion as significant predictors of turnover intentions (Sims, 2007). Rothmann and Joubert (2007) reported similar findings in a South African study and Knudsen, Ducharme and Roman (2006) confirmed a positive link between emotional exhaustion and intentions to quit in a study conducted on a sample of therapeutic counsellors.

These findings are in accordance with those of the JD-R model (Jackson et al., 2006), with the exception of the latter presenting a weaker burnout-turnover intention relationship (Schaufeli \& Bakker, 2004). Research findings of a predictive relationship between burnout and turnover intentions are not plentiful and literature regarding the strength of the relationship proved to be inconsistent; nevertheless, a clear linkage does seem to exist. Therefore, it seems that when experiencing symptoms of burnout, experiences of turnover intentions will not be far behind. In the light of this, the finding that Generation $X$ nurses experience more symptoms of burnout when compared to Baby Boomer generation nurses and that this contributes to high turnover intentions (Leiter, Jackson, \& Shaughnessy, 2009) proves to be significant. Furthermore, burnout has also been found to be the dominant predictor of depression and depression has been proven to predict turnover intentions (Anderson, 2008; Baba, Galperin, \& Lituchy, 1999).

Two respective studies found burnout to be a partial mediator between turnover intention and (1) role stressors and (2) perceived organisational politics (Fogarty, Singh, Rhoads, \& Moore, 2000; Huang, Chaung, \& Lin, 2003). Obtained research showed no indications of findings on burnout acting as mediator in a work engagement-turnover intention relationship. These findings guided the authors to the first research hypothesis to be tested.

Hypothesis 1: The relationship between work engagement and turnover intentions is mediated by burnout.

The intent to leave the organisation has also been described as the final step in a series of withdrawal cognitions leading to actual turnover (Tett \& Meyer, 1993). In a robust study which set out to differentiate the predictive strengths of several turnover antecedents, Griffeth et al. (2000) confirmed that the intention to leave was one of the greatest predictors of turnover. Predecessors in the withdrawal process were found to be predictors of voluntary employee turnover; these are job satisfaction, organisational commitment, job search behaviours, withdrawal cognitions and turnover intentions (Griffeth et al., 2000).

A number of studies (Coyne \& Ong, 2007; Hemdi \& Nasurdin, 2008; Zimmerman, 2008) have been concluded about the

1.A mediator is defined as a variable that explains the relation between a predictor variable and an outcome or predicted variable (Baron \& Kenny, 1986). organisational attitude labelled turnover intention and some interesting results were obtained. Social exchange relationships, which are partially predicted by organisational justice, were proven to have a significant predicting relationship with turnover intention (Tekleab, Takeuchi, \& Taylor, 2005). Tekleab et al. (2005) further noted that the perception of contract violation indirectly determines employee turnover intentions. It was also found that perceived inequity in employment relationships led to turnover intentions and that poor organisational commitment mediated this outcome (Geurts, Schaufeli, \& Rutte, 1999). A summary of the reviewed research surrounding the relationships between four constructs, that is, work engagement, burnout, OCB and work alienation, which affect turnover intention, will now follow.

In burnout-OCB literature, Bakker, Demerouti and Verbreke (2004) built upon Demerouti et al.'s (2001) JD-R model of burnout and established the existence of a strong and negative relationship between burnout and extra-role performance (OCB). In another study, emotional exhaustion was shown to share a positive predictive relationship with turnover intentions and a negative predictive relationship with organisational citizenship behaviour beneficial to the organisation (OCBO) and organisational citizenship behaviour beneficial to the supervisor (OCBS) (Cropanzano, Rupp, \& Byrne, 2003). To summarise, it seems that an overall negative relationship exists between burnout and citizenship-related behaviours.

Furthermore, within burnout-work alienation literature the subcomponent of burnout, namely depersonalisation, could be described in a broader sense as a withdrawal behaviour which could result in work attitudes such as alienation, disengagement and/or cynicism (Cherniss, 1980). It seems that a link exists between groups with high levels of depersonalisation and groups experiencing high levels of alienation and this in turn suggests a similar link between burnout and alienation. A critical literature review conducted on burnout and alienation even went as far as proposing that burnout should be redefined as a form of alienation (Karger, 1981).

After consulting the available research on relationships between burnout, alienation and OCB exclusively, the lack of clear-cut findings proved to be undeniable. The relationships between these three constructs are built upon incompatible foundational concepts and remain formless, specifically within the I/O psychological domain. Nevertheless, these literature findings posit a relationship between groups with high levels of burnout, groups with high levels of alienation and groups low in OCBs, although the combination of these constructs has not yet been studied. This guided the authors to the second research hypothesis to be tested.

Hypothesis 2: The group experiencing high levels of burnout will exhibit high levels of alienation, but will be low in OCBs, as opposed to the low burnout group.

Generally, five OCB dimensions are distinguishable:

- altruism

- conscientiousness (Smith, Organ, \& Near, 1983)

- courtesy

- sportsmanship

- civic virtue (Organ, 1988).

Several citizenship-like behaviours, broadly defined as 'performance that goes beyond "in-role" requirements' (cf. Moliner, Martínez-Tur, Ramos, Peiro, \& Cropanzano, 2008, p. 329), exist in the literature. Five of these well-known concepts are OCBs, extra-role behaviours, pro-social behaviours, organisational spontaneity and contextual performance (Posakoff, MacKenzie, Paine, \& Bachrach, 2000). A review of OCB literature from 1983 up to 1999 showed that approximately 30 variations of OCBs exist (Podsakoff et al., 2000). These variations have been clustered into seven categories, that is: 
- helping behaviour

- sportsmanship

- organisational loyalty

- organisational compliance

- individual initiative

- civic virtue

- self development.

(Podsakoff et al., 2000)

Within this study, focus has been maintained on the category, namely helping behaviour. Podsakoff et al. (2000, p. 516) have defined helping behaviour as 'voluntarily helping others with, or preventing the occurrence of, work-related problems'. Altruism has been theoretically linked to helping behaviours (Podsakoff et al., 2000). Contextual performance has been theoretically linked to OCBs and by means of a specific type of contextual performance (i.e. to volunteer for activities which fall outside formal job expectations; Organ, 1997), has been conceptually linked to helping behaviours.

OCB was found to be both significantly and negatively related to turnover intentions (Coyne \& Ong, 2007; Wegge, van Dick, Fisher, Wecking, \& Moltzen, 2006). Results from a study on hotel employees put forward that higher OCB intentions and lower turnover intentions were shaped when employees perceive organisational justice and fair compensation (Hemdi \& Nasurdin, 2008). Altruism, on the other hand, did not relate significantly to turnover intentions. A possible reason for this may be that altruism is directed towards interpersonallybased citizenship behaviour, rather than organisation-based. This means that withdrawal behaviours would, in the case of altruism, be directed to colleagues and clients rather than the organisation directly (Coyne \& Ong, 2007).

The availability of job resources encourages employees to become engaged in their work, which in turn fosters OCBs (Bakker et al., 2004; Salanova, Bakker, \& Llorens, 2006). OCBs result in employees exerting extra-role performance behaviours (Bakker \& Demerouti, 2007) such as taking personal initiative (Fay \& Sonnentag, 2002) and pursuing learning goals (Sonnentag, 2003). Moliner et al. (2008) also found a positive relationship between work engagement and extra-role customer service. It is apparent that the available research findings illustrate a positive correlation between work engagement and OCBs.

Bakker and Demerouti (2007) reported that employees who have the benefit of strong job resources tend to be more willing to further invest in increasing these resources. Work engagement is considered a positive resource, which means that it could have a spiral effect on positive resources and health outcomes (Mauno, Kinnunen, \& Ruokolainen, 2007). The positive spiral effect work engagement could have on resource gain outcomes is paralleled to an array of positive organisational scholarship findings (Fredrickson, 2003) and attests to the Conservation of Resources (COR) theory (Hobfoll, 2001). The broaden-and-build theory of positive emotions illuminates ways that positive emotions might broaden a person's thought capacity and develop longterm personal resources (Fredrickson, 2001). The theory further describes how the experience of positive emotions could 'fuel upward spirals toward optimal individual and organizational functioning' (Fredrickson, 2003, p. 163).

From the results of a study conducted on organisational anomie it could be inferred that groups with high levels of work-related alienation are more strongly linked to a negative attitudeOCB relationship (de Lara \& Rodríquez, 2007). Anomie is a sociological concept used to describe the social conditions of alienation (cf. Roodt, 2004a), whereas organisational anomie is very closely linked to the concept of work-related alienation (de Lara \& Rodríquez, 2007). Joubert, Crafford and Schepers (2004) also suggested a negative relationship and stated that employees exhibiting OCBs might also experience lesser work alienation.
In summary, the theoretical contributions of the positive organisational scholarship domain offer valuable insight into the expected outcomes of groups with high levels of both work engagement and OCBs. One anticipated outcome of groups with high levels of work engagement and OCBs would be diminished work alienation. This anticipation seems to be aligned with literature on the OCB-alienation relationship. However, the need to clarify the relationship between work engagement, OCB (cf. Bakker et al., 2008) and work alienation remains greatly relevant.

Another phenomenon that needs to be further examined is the work engagement-burnout continuum. The findings of a study linking Type A behaviours with burnout and work engagement (Hallberg, Johansson, \& Schaufeli, 2007), implied that work engagement and burnout may be polar opposites. Type A behaviour is defined as a pattern of behaviours that exhibit competitiveness, impatience, angry outbursts, constantly feeling pressured for time and being very energetic (Barlow \& Durand, 2005). The study reported a positive link between the Type A behaviour of acting irritable or impatient and burnout, whereas work engagement was negatively related to those behaviours (Hallberg et al., 2007). A similar line of thought will be followed when examining the work engagement - burnout relationship.

Hypothesis 3: The group with high levels of work engagement will also display high levels of OCBs, but will display low levels of alienation, as opposed to the low work engagement group.

According to Roodt (2004a), sociological literature has delivered most findings on alienation; however, the focus of work alienation follows the I/O psychological school of thought. It has been hypothesised by Kanungo (1979) that a link exists between employees with low job involvement and high levels of alienation to be more probable to leave the organisation or to withdraw effort from it.

In other social science literature, an anthropological study on alienation as a function of cultural diversity in a South African company followed an ethnographic research design and found that alienated workers, as opposed to engaged workers, minimised interaction with managers or colleagues. This decline in interaction gave rise to distancing and distrust, which led to increased alienation (Herselman, 2004). The literature review conducted on the relationship between work-related alienation and turnover intentions indicated an absence of research. To investigate this hypothesised relationship could thus add to the body of knowledge on turnover.

The literature findings of the section pertaining to the relationships shared with turnover intentions guided the authors to the fourth research hypothesis to be tested.

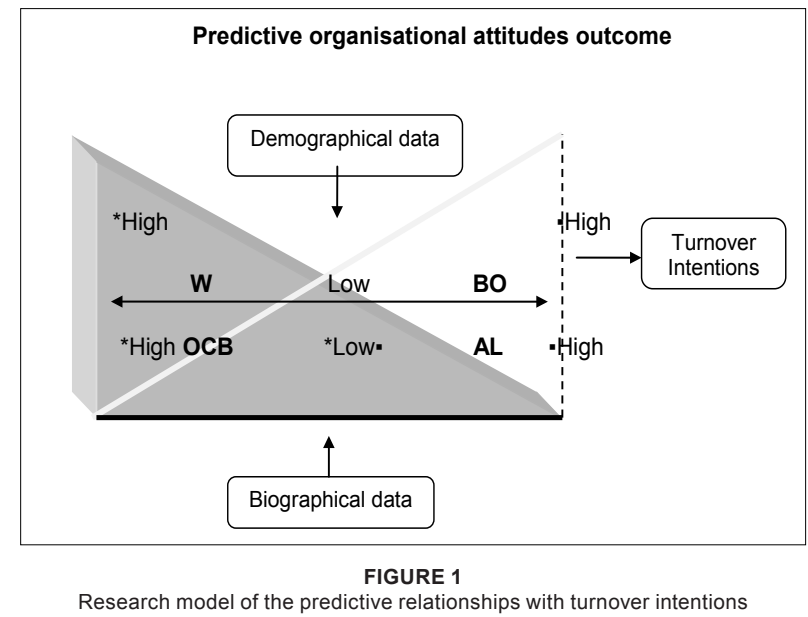

Research model of the predictive relationships with turnover intentions 
Hypothesis 4: Work engagement and OCBs will have a negative, predictive relationship with turnover intentions; whilst burnout and alienation will have a positive, predictive relationship with turnover intentions.

These hypotheses can be graphically depicted as follows:

The research model depicts that work engagement (WE) and burnout (BO) lie on a continuum, with organisational citizenship behaviour $(\mathrm{OCB})$ related to the group high on the WE scale. In contrast, work alienation (AL) will again be related to the group with high levels of BO. The model further depicts hypothesis 2 by linking three constructs (denoted with three squares) and creating a group with high $\mathrm{BO}$ and $\mathrm{AL}$, but with low levels of OCBs. The model further depicts hypothesis 3 by linking three constructs (denoted with three stars) and creating a group with high WE and OCBs, but low levels of AL. These four constructs act as predictors of turnover intentions (TI) (hypothesis 4) and both biographic and demographic variables may moderate this relationship.

\section{RESEARCH DESIGN}

\section{Research approach}

The study used a post-positivist epistemology with an analytical mode of science (Pietersen, 1989; Schurink, 1998). The study is empirical in nature and a secondary data analysis (SDA) was performed on a subsection of the dataset of Bothma and de Braine's research in progress. Bothma and de Braine's research project is a cross-sectional field survey study conducted as part of a larger Work Identity research project jointly conducted by the University of Johannesburg and Vrije University, Amsterdam. The data analyses in the study followed a correlational approach with the purpose of reaching the general and specific research objectives in an ex post facto mode.

\section{Research method}

\section{Research respondents}

A heterogeneous work force $(N=23134)$ of a large South African information and communication technologies (ICT) sector company, consisting of operational and specialist employees up to middle management, represented the unit of analysis for this study. A census approach was followed to ensure complete enumeration of the organisation. The respondent sample $(n=2$ 429 ) yielded a response rate of $11 \%$.

In Table 1 the frequency and percentages of the respondents in relation to their biographic and demographic characteristics are presented. As indicated in the last column of Table 1, the majority of the respondents were male $(63.2 \%)$, White $(44.1 \%)$ and either between the ages of 30-39 years (39.5\%) or 40-49 years (36.1\%). Most respondents were married and cohabiting (69.1\%) and indicated that their highest academic qualifications were matric or less $(40.7 \%)$, or having obtained a national diploma or national higher diploma (26.9\%). The managers and operational managers constituted $18.4 \%$ of the ICT company workforce, operational workers $54.9 \%$ and specialist workers $26.7 \%$.

\section{Measuring instruments}

The results of six measuring instruments from Bothma and de Braine's self-developed, web-based survey application were used, all of which can be completed individually. The survey was self-administered by the respondents. The authors focused on the data collected from the following forms.

Biographical and demographical data: The data were obtained in respect of all the survey respondents through their organisational registration and a form within the survey which was devoted to related questions. Their salary reference numbers were linked to the organisational enumerations which provided the necessary biographical data (gender, race, age, marital status and highest academic qualifications) and demographical data (job levels).

Utrecht Work Engagement Scale (UWES-17): The UWES-17 was used to measure work engagement and consists of three subscales labelled vigour (VI), dedication (DE) and absorption (AB) (Schaufeli \& Bakker, 2003; Schaufeli et al., 2002). The UWES was used in the majority of work engagement research studies in the literature (Bakker et al., 2008; Hakanen et al., 2006; Hakanen, Schaufeli, \& Ahola, 2008; Simpson, 2008).

TABLE 1

Biographical and Demographic Characteristics of Respondents $(n=2429)$

\begin{tabular}{llcc}
\hline Variable & Category & Frequency $(f)$ & Percentage \\
\hline Gender & Male & 1536 & 63.2 \\
& Female & 893 & 36.8 \\
Race & Black & & 26.3 \\
& White & 640 & 44.1 \\
& Coloured & 1070 & 16.3 \\
& Asian or Indian & 395 & 13.3 \\
Age in years & & 324 & 12.0 \\
& $19-29$ & 292 & 39.5 \\
& $30-39$ & 960 & 36.1 \\
Marital status & $40-49$ & 877 & 12.4 \\
& 50+ & 300 & \\
& & & 21.0 \\
Highest academic qualification & Single & 511 & 69.1 \\
& Married and cohabiting & 1678 & 9.90 \\
& Divorced or separated or widowed & 240 & 40.7 \\
Job level & Matriculated or less & 988 & 19.7 \\
& Post-school certificate or diploma & 479 & 26.9 \\
& National diploma or national higher diploma & 653 & 12.7
\end{tabular}


The 17-item, well-validated instrument delivered relatively consistent findings across different cultures, that is, the internal consistencies are widely held to be acceptable according to the respective international studies (Bakker et al., 2008). For example, the estimated Cronbach alpha coefficients of the three subscales of a South African study were 0.78 (VI), 0.89 (DE) and 0.78 (AB) (Storm \& Rothmann, 2003) and those of a Spanish study using two samples were 0.78 and 0.79 (VI), 0.84 and 0.89 (DE) and 0.73 and $0.72(\mathrm{AB})$ respectively (Schaufeli et al., 2002). The VI and $\mathrm{AB}$ subscales of these two examples either yielded borderline reliability coefficients or fell short of the acceptable 0.80 or greater psychometric guideline (Nunnally, 1978). A South African study on work engagement yielded a one-factor internal consistency of 0.92 (Storm \& Rothmann, 2003) and a Japanese study confirmed this Cronbach alpha coefficient $(\alpha=0.92)$ (Shimazu, Schaufeli, Kosugi, Suzuki, Nashiwa, Kato, Sakamoto, Irimajiri, Amano, Hirohata, Goto, \& Kitaoka-Higashiguchi, 2008).

A wide array of translated test-forms is available (cf. Schaufeli, 2009; Schaufeli \& Bakker, 2003) which show that the UWES is an accessible and trusted instrument. In this study, the UWES items were scored on a 7-point Likert (frequency rating) scale ranging from 0 ('never') to 6 ('everyday').

The VI subscale has six items, for example, 'At my work, I feel bursting with energy'. The DE subscale has five items, for example, 'I find the work that I do full of meaning and purpose'. The $A B$ subscale has six items, for example, 'I get carried away when I'm working'. The rationale of the instrument is that high levels of VI and DE suggest work engagement (Schaufeli \& Bakker, 2003; Schaufeli et al., 2002).

Maslach Burnout Inventory-Human Services Survey (MBIHSS-20): The MBI-HSS-20 was used to measure burnout and consists of three subscales labelled emotional exhaustion (EE), depersonalisation(DP) and diminished personal accomplishment (PA) (Maslach \& Jackson, 1981; Maslach, Jackson, \& Leiter, 1997; Vanheule, Rosseel, \& Vlerick, 2007). Maslach and Jackson (1981) conducted a series of psychometric analyses on the MBI, which confirmed it as a valid and reliable measuring instrument. The 25-item MBI's internal consistency was estimated by means of Cronbach alpha and yielded a reliability coefficient of 0.83 (in respect of frequency) and 0.84 (intensity) (Maslach \& Jackson, 1981)

The MBI-HSS-20 omitted two items from the original MBI-HSS (Maslach \& Jackson, 1981), due to their lack of factorial validity (Byrne, 1993; Schaufeli \& Van Dierendonck, 1993). A South African study for SAPS members established the construct validity of the adapted and translated versions of the MBI-GS for English, Afrikaans and Setswana speaking groups (Marais, Mostert, \& Rothmann, 2009). For the stated reasons and due to the finding that the MBI is the most often used for measuring burnout (over $90 \%$ of journal articles and dissertations used the MBI) (Schaufeli \& Enzmann, 1998), this 20-item instrument was used. Similar to the UWES, the items were scored on a 7-point Likert (frequency rating) scale ranging from 0 ('never') to 6 ('everyday')

The EE subscale has eight items, for example 'I feel emotionally drained from my work'. The DP subscale has five items, for example, 'I don't really care what happens to some recipients'. The diminished PA subscale has seven items, for example, 'In my work, I deal with emotional problems very calmly'. A Dutch study yielded the following Cronbach alpha coefficients for the three subscales: 0.80 (EE), 0.64 (DP) and 0.74 (PA) (Kop, Euwema, \& Schaufeli, 1999); inconclusive results were obtained regarding the reliability of the DP and diminished PA subscales (cf. Cramer, 2003; cf. Nunnally, 1978). However, the psychometric properties of most of the MBI studies on human service professions, generally documented Cronbach alpha coefficients of 0.70 and higher (Schaufeli, Bakker, Hoogduin, Schaap, \& Kladler, 2001). The rationale of the instrument is that high levels of EE and DP and low levels of PA suggest burnout (Maslach \& Jackson, 1981).

Helping behaviour questions: The helping behaviour questions were used to measure organisational citizenship behaviour. The questions consist of five items of the Helping Behaviour Scale (Van Dyne \& LePine, 1998) and four items focused on the Altruism dimension of the Citizenship Behaviour Scale (Smith et al., 1983). The measurement of helping behaviour questions was done by means of nine items, for example, 'How often do you assist others with their work for the benefit of your work group?' All items were scored on a 7-point Likert (frequency rating) scale ranging from 1 ('never') to 7 ('always').

Alienation scale: The alienation scale was used to measure work alienation and consists of two subscales (Korman, Wittigberman, \& Lang, 1981) labelled Personal Alienation (five items) and Social Alienation (three items). The scale used in this study was tailored by combining two separate measures; that is, the 18item Alienation measure of Korman et al. (1981) and the 24-item Alienation scale of Dean (1961). The 18-item Alienation measure yielded an acceptable reliability coefficient of 0.83 (Banai, Reisel, \& Probst, 2004) and the 24-item Alienation measure yielded a borderline reliability coefficient of 0.78 (Dean, 1961). The alienation scale has eight items, for example, 'To what extent do you feel that your daily activities don't reflect your real interests and values?'. This response scale was scored on a 7-point Likert scale varying between poles of intensity. The response scale ranged, for example, from 1 ('very much so') to 7 ('not at all'). However, within this study the focus was exclusively on the subscale Personal Alienation due to its superior relevance to work alienation.

Turnover Intentions Questionnaire: The Turnover Intentions Questionnaire developed by Roodt (2004b) was used to measure employee intentions of either staying with or leaving an organisation. Two earlier studies (Jacobs, 2005; Martin \& Roodt, 2007) proved Roodt's (2004b) questionnaire to be both reliable ( $\alpha=0.913$ and $\alpha=0.895$ respectively) and valid. The six most reliable items were used in the construction of the distributed survey, for example, 'How often have you considered leaving your job?'. The response scale was scored on a 7-point Likert scale varying between poles of intensity. The scale ranged, for example, from 1 ('never') to 7 ('always').

\section{Research procedure}

An invitation was sent out by means of e-mail communications to each employee within the sample to participate in the research project. The invitation also explained the purpose and significance of the study and included a certificate guaranteeing the confidentiality of the respondents. A web-link was added to each invitation, which provided the respondents with direct access to a web-based survey application. The layout of the web-based application offered versatility in the completion procedures as it enabled employees to complete the survey instruments one at a time.

The confidentiality of respondents was protected by means of complying with the company policy of using the employees' personnel numbers as identifiers, which were deleted from the database when the data was still in raw form. The responses were captured in a Structured Query Language (SQL) database that monitored the responses and restricted it to one per individual, in accordance with the personnel number. The data was immediately available and the SQL database sent out reminders to non-respondents.

\section{Statistical analysis}

The SPSS programme Version 15 (Pallant, 2007) was used for the statistical analyses that were conducted by Statkon, the statistical consultation service of the University of Johannesburg. First- 
TABLE 2

Bartlett's Test of Sphericity and Kaiser-Meyer-Olkin's Measure of Sampling Adequacy Values of All Scales

\begin{tabular}{lccc}
\hline Scales & \multicolumn{2}{c}{ Bartlett's test of Sphericity } & Kaiser-Meyer-Olkin of MSA \\
\cline { 2 - 3 } & $\chi^{2}$ & 0.000 & 0.962 \\
Work engagement (WE) & 30846.956 & 0.000 & 0.909 \\
Burnout (BO) & 17790.323 & 0.000 & 0.887 \\
Organisational citizenship behaviour (OCB) & 10631.027 & 0.000 & 0.787 \\
Work alienation (AL) & 7406.932 & 0.000 & 0.838 \\
Turnover intverventions (TI) & 4302.361 & 0 & \\
\hline
\end{tabular}

All scales are significant at the $p \leq 0.001$ level

$\chi^{2}$, chi-square; MSA, Measure of Sampling Adequecy

and second-order confirmatory factor analyses were conducted to determine the factor structures of the scales. Iterative item analyses were conducted on all scales to assess their internal consistency reliabilities (Cronbach alpha coefficients). The inferential statistics performed for hypothesis testing comprised of multiple regression analyses, ANOVAS and independent sample $t$-tests.

\section{RESULTS}

\section{Factor and reliability analyses}

The large sample size of the study $(n=2429)$ and the acceptable Kaiser-Meyer-Olkin (KMO) of Measure of Sampling Adequacy (MSA) and Bartlett's Test of Sphericity values generated by the SPSS programme Version 15 (Pallant, 2007) established the appropriateness for factor analyses.

Results from these tests are reported as follows.

From Table 2 it is clear that the Bartlett's Test of Sphericity yielded chi-square values in respect of the scales WE, BO, OCB, $\mathrm{AL}$ and TI that are all statistically significant $(p=0.000)$. This indicates the suitability of the data for factor analysis. The KMO of MSA values for the five scales were all above the minimum value (0.6), which is also indicative of the factorability of the scales. A confirmatory, first-order factor analysis was conducted on scales $\mathrm{WE}, \mathrm{BO}, \mathrm{OCB}, \mathrm{AL}$ and $\mathrm{TI}$ and an additional secondorder factor analysis was conducted on the three subscales of $\mathrm{WE}$ and $\mathrm{BO}$. The single factor structures of the three subscales of the UWES-17, namely VI ( 6 items), DE (5 items) and AB ( 6 items) and the three MBI-HSS-20 subscales EE (8 items), DP (5 items) and PA (7 items) were confirmed.

The principal axis factor analysis method was used, followed by a Varimax rotation for first-order factor analyses and an Oblimin rotation for second-order factor-analyses, followed by Kaiser's (1970) criterion and a scree test. All scales yielded a single factor structure where all items load onto the particular scale, which is indicative of the factorial validity of the scales. An iterative item reliability analysis was conducted on all items for each scale. Acceptable reliabilities were obtained for all scales and are presented in brackets on the diagonal of the intercorrelation matrix in Table 3. In Table 3 the means, standard deviations, reliability coefficients and Pearson correlation coefficients of the $\mathrm{WE}, \mathrm{BO}, \mathrm{OCB}, \mathrm{AL}$ and $\mathrm{TI}$ scales are presented.
Not shown in Table 3 are WE's three subscales, that is, VI, DE and $A B$, which yielded Cronbach alpha coefficients $(\alpha)$ of 0.880 , 0.911 and 0.859 respectively. BO's three subscales, namely EE, DP and Diminished PA yielded Cronbach alpha coefficients of $0.887,0.701$ and 0.707 respectively. AL (Personal Alienation) yielded a Cronbach alpha coefficient of 0.812 . Overall the scales have acceptable reliability coefficients for proceeding with the next phase of the statistical analysis.

\section{Mediation analysis}

In Figure 2, the first hypothesis is graphically represented and predicts that the relationship between WE and TI is mediated by BO. Three issues were considered when the test for mediation was designed for this study. Firstly, the effect that correlations amongst the predictor, mediator and outcome have on the power of the test of mediation was determined (Frazier et al., 2004). In the present study, the Pearson correlation coefficient $(r=-0.518$ as depicted in Table 2) established a strong, negative relationship between WE (predictor) and BO (mediator). A formula to determine the effective sample size for tests of mediation was utilised and, due to the high correlation between $\mathrm{WE}$ and $\mathrm{BO}$, the power of the mediation test was reduced to that of a sample size of 1777 .

Secondly, Frazier et al. (2004) explained that the power of tests of mediation is greatest when relationships of path $b$ and path a present comparable correlation coefficients and, furthermore, when the strength of the relationship of path $b$ exceeds the strength of the relationship of path a. In the present study, the Pearson correlation coefficient of BO (mediator) with TI (outcome) is comparatively similar, but greater than the Pearson correlation coefficient of WE (predictor) with BO (mediator) $(0.564>-0.518)$. Furthermore, the reliability of the measure of the mediator should be considered (Frazier et al., 2004). In the current study, the reliability coefficient of the MBI-HSS-20 was estimated at 0.836 , which is adequate according to Nunnally (1978).

Baron and Kenny's (1986, p. 1176) 'causal chain' method to establishing a mediation relationship through testing three multiple regressions was used. In the current study, an analysis of variance (ANOVA) was conducted on the four mediation relationships, which showed that the obtained multiple regressions were highly significant for all $(p=0.000)$. The multiple linear regression method was used. Firstly, the

TABLE 3

Means, standard deviations, reliability coefficients and correlation coefficients of all scales $(n=2429)$

\begin{tabular}{|c|c|c|c|c|c|c|c|}
\hline Scales & $M$ & $S D$ & WE & BO & OCB & $\mathrm{AL}$ & $\mathrm{TI}$ \\
\hline Work engagement (WE) & 4.502 & 1.238 & $(0.952)$ & $-0.518+\dagger \dagger$ & $0.349 \dagger \dagger$ & $-0.621 \dagger \dagger \dagger$ & $-0.581 \dagger \dagger \dagger$ \\
\hline Burnout (BO) & 2.058 & 0.925 & - & $(0.836)$ & $-0.211 \dagger$ & $0.523+\dagger \dagger$ & $0.564 \uparrow \dagger \dagger$ \\
\hline Organisational citizenship behaviour (OCB) & 5.485 & 0.963 & - & - & $(0.863)$ & $-0.131 \dagger$ & $-0.108 \dagger$ \\
\hline Work alienation (AL) & 4.094 & 1.442 & - & - & - & $(0.812)$ & $0.733+\dagger \dagger$ \\
\hline Turnover intverventions (TI) & 4. 02 & 1.357 & - & - & - & - & $(0.800)$ \\
\hline
\end{tabular}

$M$, mean; $S D$, standard deviation; $\alpha$ 's, Cronbach's alpha coefficients, appear on the diagonal in brackets

$\dagger$, Correlations ranging between $0.10 \leq r \leq 0.29$ (small effect); $\dagger$, Correlations ranging between $0.30 \leq r \leq 0.49$ (medium effect); $\dagger \dagger$, Correlations ranging between $0.50 \leq r \leq 1.0$ (large effect)

WE, work engagement; $\mathrm{BO}$, burnout; OCB, organisational citizenship behaviour (OCB); AL, work alienation; TI, turnover interventions 
TABLE 4

Regression Coefficients of Mediation Relationships Unstandardised regression coefficients

\begin{tabular}{llll}
\multicolumn{4}{c}{ Unstandardised regression coefficients } \\
\hline Relationships (Paths) & B & Standard errors & $p$ \\
\hline Path c & -0.637 & 0.018 & 0.000 \\
Path a & -0.387 & 0.013 & 0.000 \\
Path b & 0.527 & 0.026 & 0.000 \\
Path ć & -0.433 & 0.020 & 0.000 \\
\hline
\end{tabular}

All paths are significant at the $p \leq 0.001$ level

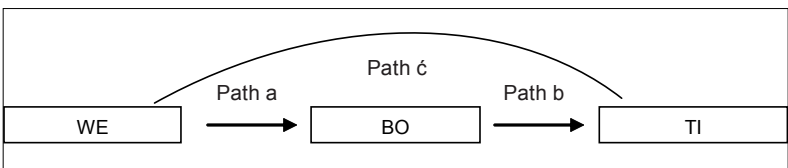

Adapted from Frazier, P.A., Tix, A.P., \& Barron, K.E. (2004). Testing moderator an mediator effects in counseling psychology. Journal of Counseling Psychology, 51, 115-134. FIGURE 2

Research model linking WE to TI by means of burnout.

relationship between WE (predictor) and TI (outcome) was established (path c). Secondly, the relationship between WE (predictor) and $\mathrm{BO}$ (mediator) was established (path a). Thirdly, the relationship between $\mathrm{BO}$ (mediator) and TI (outcome) was established (path $b$ ), as well as the estimated relationship between WE and TI controlling for BO (path ć). Table 4 indicates the regression coefficients of each path.

In Table 4 , each path is shown as statistically significant $(p=$ $0.000)$. It is evident that (in absolute terms) path ć $(-0.433)$ is significantly smaller than path c $(-0.637)$, which suggests a partial mediation relationship. The significance of the mediated effect was tested through computing the product of paths ' $a$ ' and ' $b$ ' (0.204) and dividing it by the standard error term (0.012) described by Baron and Kenny (1986). The standard error term used is the square root of $b^{2} s a^{2}+a^{2} s b^{2}+s a^{2} s b^{2}$, where $a$ and $b$ are unstandardised regression coefficients and $s a$ and $s b$ are their standard errors (Baron \& Kenny, 1986; Frazier et al., 2004).
The analysis yielded a $z$ score of the mediated effect and this $z$ score $(Z=16.748)$ confirmed the mediated effect to be highly significant $(p \leq 0.001)$. Therefore, the data supports the alternative hypothesis that the relationship between WE and TI is partially mediated by $\mathrm{BO}$ and rejects the null hypothesis.

The second hypothesis (graphically represented in Figure 1) predicts that the high $\mathrm{BO}$ groups will obtain statistically significant higher AL scores, but statistically significant lower OCB scores than low BO groups. An independent sample $t$-test was used to determine whether there are statistically significant differences in the mean scores of $\mathrm{AL}$ and OCB in respect of low and high $\mathrm{BO}$ groups and the results are shown in Table 5. Firstly, Levene's Test for Equality of Variances indicates whether the variances of the AL and OCB scores are equal for low and high $\mathrm{BO}$ groups. For $\mathrm{AL}(p=0.484)$ the variances were assumed equal and for OCB $(p=0.000)$ the variances were assumed unequal.

It is clear from Table 5 that there are mean score differences between low and high $\mathrm{BO}$ groups in respect of the $\mathrm{AL}$ and OCB scores. In order to test whether these differences are statistically significant, a $t$-test for Equality of Means (2-tailed) was conducted. The significance column in Table 6 shows significant differences for the AL and OCB mean scores.

From Table 6 it is clear that there are statistically significant differences $(p=0.000)$ between low and high $\mathrm{BO}$ groups in respect of the AL and OCB mean scores. Therefore, the data supports the alternative hypothesis that the group with high levels of $\mathrm{BO}$ also score highly on $\mathrm{AL}$, but are low on OCBs, as opposed to the low $\mathrm{BO}$ group.

The third hypothesis (graphically represented in Figure 1) predicts that the group with high WE scores will obtain statistically significantly lower AL scores, but statistically significantly higher OCB scores, than low WE groups. In a similar vein as the above stated hypothesis, an independent sample $t$-test was also done to determine whether there are statistically significant

TABLE 5

Means and standard deviations of low and high burnout groups' work alienation and organisational citizenship behaviourscores and equality of variances tests $(n=2429)$

\begin{tabular}{|c|c|c|c|c|c|c|c|c|}
\hline & \multirow[b]{2}{*}{ BO $M d n$} & \multirow[b]{2}{*}{$N$} & \multirow[b]{2}{*}{$M$} & \multirow[b]{2}{*}{$S D$} & \multirow[b]{2}{*}{ Std. Error $M$} & & \multicolumn{2}{|c|}{ Levene's Test for Equality of Variances } \\
\hline & & & & & & & $F$ & $p$ \\
\hline \multirow[t]{2}{*}{ Work alienation (AL) } & Low BO & 1210 & 3.479 & 1.304 & 0.037 & Equal variances & 0.489 & 0.484 \\
\hline & High BO & 1219 & 4.705 & 1.307 & 0.037 & assumed & & \\
\hline \multirow[t]{2}{*}{ Organisational citizenship behaviour (OCB) } & Low BO & 1210 & 5.627 & 0.885 & 0.025 & Equal variances & 18.727 & $0.000^{*}$ \\
\hline & High BO & 1219 & 5.343 & 1.014 & 0.029 & not assumed & & \\
\hline
\end{tabular}

$M d n$, Median, $N$, Sample size; $M$, Mean; $S D$, Standard deviation, BO, burnout

*, Statistically significant $(p \leq 0.001)$

TABLE 6

Independent sample t-tests for low and high burnout groups' work alienation and organisational citizenship behaviour scores $(n=2429)$

\begin{tabular}{|c|c|c|c|c|c|}
\hline & & \multicolumn{4}{|c|}{$t$-test for Equality of Means } \\
\hline & & $t$ & $d f$ & $p$ (2-tailed) & Mean differences \\
\hline Work alienation (AL) & Equal variances assumed & -23.152 & 2427 & 0.000 & -1.226 \\
\hline Organisational citizenship behaviour (OCB) & Equal variances not assumed & 7.365 & 2387.909 & 0.000 & 0.284 \\
\hline
\end{tabular}

$d f$, degrees of freedom

All $t$-values are significant at the $p \leq 0.001$ level

TABLE 7

Means and standard deviations of low and high work engagement groups' work alienation and organisational citizenship behaviour scores and equality of variances tests $(n=2429)$

\begin{tabular}{|c|c|c|c|c|c|c|c|c|}
\hline & \multirow[b]{2}{*}{ WE Mdn } & \multirow[b]{2}{*}{$N$} & \multirow[b]{2}{*}{$M$} & \multirow[b]{2}{*}{$S D$} & \multirow[b]{2}{*}{ Std. Error $M$} & & \multicolumn{2}{|c|}{ Levene's Test for Equality of Variances } \\
\hline & & & & & & & $F$ & $p$ \\
\hline \multirow[t]{2}{*}{ Organisational citizenship behaviour (OCB) } & Low WE & 1159 & 5.204 & 1.018 & 0.029 & Equal variances & 40.444 & $0.000^{*}$ \\
\hline & High WE & 1270 & 5.74 & 0.831 & 0.023 & not assumed & & \\
\hline \multirow[t]{2}{*}{ Work alienation $(\mathrm{AL})$} & Low WE & 1159 & 4.895 & 1.232 & 0.036 & Equal variances & 2.130 & 0.145 \\
\hline & High WE & 1270 & 3.364 & 1.214 & 0.034 & assumed & & \\
\hline
\end{tabular}

$M d n$, Median, $N$, Sample size; $M$, Mean; $S D$, Standard deviation, WE, work engagement

${ }^{*}$, Statistically significant $(p \leq 0.001)$ 
TABLE 8

Independent sample t-tests for low and high work engagement groups' work alienation and organisational citizenship behaviour scores $(\mathrm{n}=2429)$

\begin{tabular}{|c|c|c|c|c|c|}
\hline & & \multicolumn{4}{|c|}{$t$-test for Equality of Means } \\
\hline & & $t$ & $d f$ & $p$ (2-tailed) & Mean differences \\
\hline Organisational citizenship behaviour (OCB) & Equal variances not assumed & -14.140 & 2238.842 & 0.000 & -0.536 \\
\hline Work alienation (AL) & Equal variances assumed & 30.829 & 2427 & 0.000 & 1.531 \\
\hline
\end{tabular}

$d f$, degrees of freedom

All $t$-values are significant at the $p \leq 0.001$ level

differences in the mean scores of OCB and AL in respect of the low and high WE groups. Firstly, Levene's Test for Equality of Variances (Table 7) indicates whether the variances of the OCB and AL scores are equal for high and low WE groups. For AL $(p=0.145)$ the variances were assumed equal and for OCB $(p=$ $0.000)$ the variances were assumed unequal.

It is clear from Table 7 that there are mean score differences between low and high WE groups in respect of the OCB and AL scores. The $t$-test for Equality of Means (2-tailed) was conducted to test for statistically significant differences. The significance column in Table 8 shows significant differences between high and low $\mathrm{BO}$ groups for $\mathrm{OCB}$ and $\mathrm{AL}$ mean scores.

From Table 8 it is clear that there are statistically significant differences $(p=0.000)$ for low and high WE groups in respect of the OCB and AL mean scores. Therefore, the data supports the alternative hypothesis that the group high on WE is also high on OCBs, but low on AL, as opposed to the low WE group. High $\mathrm{WE}$ and low BO thus show similar effects in respect of the AL and OCB scores. And again, low WE and high BO show similar effects in respect of the AL and OCB scores, thereby suggesting that $\mathrm{WE}$ and $\mathrm{BO}$ may be polar opposites.

The fourth hypothesis (graphically depicted in Figure 1) postulates that $\mathrm{WE}$ and OCBs will have a negative, predictive relationship to TI; whilst $\mathrm{BO}$ and $\mathrm{AL}$ will have a positive, predictive relationship to TI. In Table 3, the Pearson correlation coefficients of the predictor variables $\mathrm{WE}, \mathrm{BO}, \mathrm{OCB}$ and $\mathrm{AL}$ with TI are presented. The correlation coefficients of both WE and OCB are negatively related to TI $\left(r_{\text {(df }=2428 ; p \leq 0.01)}=-0.581\right.$ and $r_{\text {(df }}$ $2428 ; p \leq 0,01)=-0.108$ respectively), with statistical significance and a concomitant low practical significance level. The correlation coefficients of both $\mathrm{BO}$ and $\mathrm{AL}$ are positively related to TI $\left(r_{\text {(df }=2428 ; p \leq 0.01)}=0.564\right.$ and $r_{(\mathrm{df}=2428 ; p \leq 0.01)}=0.733$ respectively), with statistical significance and a concomitant high practical significance level. Therefore, on a bivariate level the data supports the alternative hypothesis that WE and OCBs have a negative predictive relationship to TI; whilst $\mathrm{BO}$ and $\mathrm{AL}$ have a positive predictive relationship to TI.

To explore this relationship further on a multi-variate level, an ANOVA was conducted on each of the predictor variables $\mathrm{WE}, \mathrm{BO}, \mathrm{OCB}$ and AL. The $F$ statistics in respect of $\mathrm{WE}, \mathrm{BO}$, OCB and AL are all statistically significant $(p=0.000)$. The null hypotheses were rejected and a linear relationship between each of the predictor variables and TI were established. The stepwise multiple regression method was used and the model summary in Table 9 reflects the different properties of the regression model.

In Table 9, the multiple correlation coefficients $(R)$ between the predictor variables of each model and the predicted variable (TI) are presented. The obtained variance $\left(R^{2}\right)$ is the proportion of the variance that is attributable to the regression equation of TI. The Adjusted $R^{2}$ is the corrected version of the $R^{2}$ to better fit the population and is used to compare the models with other predictor models. The regression analysis of the model accounted for $59.6 \%$ of the variance of TI of the sample group $\left(\Delta R^{2}=0.596\right)$. The regression coefficients are ranked in Table 9, from the predictor variable contributing the most variance to the least, when the variance explained by the other variables in the model is controlled. The beta coefficients reflect the regression weights that each predictor variable carries in the prediction of TI.

In Table 9, the stepwise multiple regression coefficients $\left(R^{2}\right)$ of $\mathrm{AL}, \mathrm{BO}, \mathrm{WE}$ and $\mathrm{OCB}$ in predicting $\mathrm{TI}$ are provided. The significance levels $(p=0.000)$ of all the predictor variables listed in Table 9 are less than the critical value of 0.001 and therefore uniquely contribute to the prediction of TI. The regression equation for the prediction of TI can be formulated as:

\section{$\mathbf{T I}=1.836+0.495 \mathrm{AL}+0.318 \mathrm{BO}-0.180 \mathrm{WE}+0.091 \mathrm{OCB}$}

Thus, evidence for the support of the alternative hypothesis of hypothesis 4 is hereby provided.

\section{DISCUSSION}

The main purpose of the study was to determine whether different constructs such as work engagement, burnout, OCB and work alienation are related to (and predictors of) turnover intentions. To the authors' knowledge this is the first study that includes the WE-BO continuum and constructs, such as OCB and work alienation as predictors of TI. In addition, WE and OCB were related to TIs in a negative and predictive manner and $\mathrm{BO}$ and $\mathrm{AL}$ were related to TIs in a positive and predictive manner.

\section{Summary of results}

Overall the scales and subscales used in the study yielded acceptable reliability coefficients, which is indicative of the internal consistency of the scales in relation to the ICT sector sample group. These reliabilities are shown in Table 3 and

TABLE 9

Stepwise multiple regression of work alienation, burnout, work engagement and organisational citizenship behaviour on turnover intervention

\begin{tabular}{|c|c|c|c|c|c|c|c|c|}
\hline \multirow[b]{2}{*}{ Predictor variables } & \multirow[b]{2}{*}{$R$} & \multirow[b]{2}{*}{$R^{2}$} & \multirow[b]{2}{*}{ Standardised $R^{2}$} & \multicolumn{2}{|c|}{$\begin{array}{l}\text { Unstandardised } \\
\text { Coefficients }\end{array}$} & \multirow{2}{*}{$\begin{array}{c}\begin{array}{c}\text { Standardised } \\
\text { Coefficients }\end{array} \\
\text { Beta } \\
\end{array}$} & \multirow{2}{*}{$-t$} & \multirow[b]{2}{*}{$p$} \\
\hline & & & & B & Standard errors & & & \\
\hline Constant & & & & 1.836 & 0.160 & & 11.485 & 0.000 \\
\hline Work alienation (AL) & $0.733 a$ & 0.538 & 0.537 & 0.495 & 0.016 & 0.526 & 30.196 & 0.000 \\
\hline Burnout (BO) & $0.763^{\mathrm{b}}$ & 0.582 & 0.582 & 0.318 & 0.023 & 0.217 & 13.684 & 0.000 \\
\hline Work engagement (WE) & $0770^{\circ}$ & 0.593 & 0.592 & -0.180 & 0.020 & -0.164 & -9.085 & 0.000 \\
\hline Organisational citizenship behaviour (OCB) & $0.772^{\mathrm{d}}$ & 0.597 & 0.596 & 0.091 & 0.020 & 0.064 & 4.624 & 0.000 \\
\hline
\end{tabular}

All regression coefficients are significant at the $p \leq 0.001$ level

a, Predictor: (Constant), AL; b, Predictors: (Constant), AL, BO; c, Predictors: (Constant), AL, BO, WE; d, Predictors: (Constant), AL, BO, WE, OCB; e, Dependent variable: TI

WE, work engagement; $B O$, burnout; $\mathrm{OCB}$, organisational citizenship behaviour (OCB); AL, work alienation; TI, turnover interventions 
mentioned in the discussion that follows Table 3. The study yielded even greater reliability coefficients for the UWES $(\alpha=$ 0.952) and its subscales than reported in the relevant literature (cf. Schaufeli et al., 2002; Shimazu et al., 2008; Storm \& Rothmann 2003). According to the psychometric guideline of a 0.80 acceptance level for Cronbach alpha coefficients (Nunnally, $1978)$, the MBI-HSS subscales, DP $(\alpha=0.701)$ and diminished PA ( $\alpha=0.707)$ seem to provide inconclusive results as to whether it is reliable or not. However, the reliability coefficients of these two subscales were consistent with previous research findings (Kop et al., 1999; Schaufeli et al., 2001) and are not isolated cases.

Hypothesis 1 tested for a mediation effect of $\mathrm{BO}$ in the predictive relationship between $\mathrm{WE}$ and TI and the results supported the hypothesis. According to the reviewed literature, this particular mediation relationship has never been tested before. The different variables were regressed onto one another and the test for mediation showed the effect to be highly significant. However, the relationship between WE and TI is only partially mediated by BO. This finding comes as no surprise, seeing that two previous studies (Fogarty et al., 2000; Huang et al., 2003), albeit with different predictor variables, also found BO to only partially mediate similar BO relationships with TI. The tendency of $\mathrm{BO}$ to mediate relationships with TI only to a partial extent may point to the possibility of multiple variables mediating this relationship. Therefore, BO's mediation effect may be constrained to partiality in the relationship between WE and TI, due to multiple mediators contributing to this effect.

Both hypotheses 2 and 3 were confirmed by the results of the independent $t$-tests conducted (refer to Tables 5-8) and both delivered results of combination variables that has not been reported in previous literature. Hypothesis 2 stated that high BO groups will obtain statistically significantly higher AL scores, but statistically significantly lower OCB scores than low $\mathrm{BO}$ groups. The opposite relations were postulated for low BO groups.

Hypothesis 3 stated that groups with high levels of WE will obtain statistically significantly higher OCB scores, but statistically significantly lower AL scores than low WE groups. The opposite relations were postulated for low WE groups. The confirmation of this hypothesis also provides support for the effectiveness of the broaden-and-build theory of positive emotions (Fredrickson, 2001) and the COR theory (Hobfoll, 2001) regarding the upward spiral effect of positive emotions and anticipated outcomes of groups with high levels of both WE and OCB.

The existence of the WE-BO continuum is also supported by the results of hypotheses 2 and 3, which illustrate that similar results were obtained for high WE groups and low BO groups and high $\mathrm{BO}$ groups and low WE groups. These results are aligned with those of a study linking Type A behaviour with $\mathrm{BO}$ and WE (Hallberg et al., 2007) that suggested the functioning of the WE$\mathrm{BO}$ continuum in a similar indirect manner. However, it has to be made clear that separate measuring instruments for WE and BO, the UWES-17 and the MBI-HSS-20, were used for this study. The rationale behind measuring WE as a separate construct from $\mathrm{BO}$ and vice versa, is the recognised theoretical subcomponents of each of the two constructs. WE is characterised by vigour, dedication and absorption (Schaufeli \& Bakker, 2004), whilst $\mathrm{BO}$ is characterised by emotional exhaustion, depersonalisation and diminished personal accomplishment (Maslach \& Jackson, 1981). The single-factor structures of the three subscales of both $\mathrm{WE}$ and BO were also confirmed in this study. Therefore, it is not suggested that $\mathrm{WE}$ and $\mathrm{BO}$ are inseparable and co-dependent constructs, but rather that $\mathrm{WE}$ and $\mathrm{BO}$ may be polar opposites.

Hypothesis 4 was firstly addressed on a bivariate level (refer to Table 3). The negative, predictive relationship of WE and OCB with TI and the positive, predictive relationship of BO and AL with TI were confirmed. Secondly, the hypothesised predictive relationship of $\mathrm{WE}, \mathrm{BO}, \mathrm{OCB}$ and $\mathrm{AL}$ with TI was tested on a multi-variate level (refer to Table 9). All the predictor variables were found to uniquely contribute to the prediction of TI, with $\mathrm{AL}$ contributing the most variance, then $\mathrm{BO}$, followed by $\mathrm{WE}$ and lastly OCB.

\section{Managerial implications and recommendations}

The study explored various antecedents of TI, which indicated that individuals who exhibit WE and OCB qualities are less likely to experience TIs, whilst those who exhibit BO and AL symptoms are more likely to experience TIs. The aim of the study described in this article was to increase management's understanding of the voluntary employee turnover process and, in doing so, improve the management of employee turnover statistics and its associated costs. The costs associated with the departure and replacement of employees can have a significant and detrimental effect on an organisation (Bluedorn, 1982).

This study analysed the events leading up to voluntary employee turnover. Certain indicators of TIs, such as the BO and AL levels of employees, have been identified. Certain work experiences, such as WE and OCBs, were found to reduce TI. These results could be applied in the construction of evidencebased recruitment and selection procedures, retention strategies and training and development interventions. A possible scenario where it will be beneficial to the organisation to make use of a selection instrument that also taps into the turnover propensities of candidates is that of a civil engineer vacancy. The employer would want to select a candidate less likely to quit for the duration of important projects. Also, in situations where management wishes to safeguard the company's clientele, as in the case of lawyers and marketing consultants, a similar selection procedure would prove beneficial. Therefore, human resource (HR) practices could benefit from the predictive validity this study provides and it could be used in the reduction of employee turnover.

The results may increase the accuracy of anticipated employee turnover expenses or may be used to reduce employee turnover and its associated costs (cf. Bluedorn, 1982). One specific managerial challenge is employee retention. Employee retention has become a more complex business outcome to pursue, seeing that high-potential (high flyer) employees tend to leave an organisation first. This is due to the plentiful options outside of the organisation offered by global or local competitors (Ready, Hill, \& Conger, 2008). The results of this study could also be used to address some of the talent management and human capital issues modern-day organisations are grappling with. The practical implications of the study will, therefore, impact on all the HR value chain activities, ranging from employee entrance level right through to employee exit level.

\section{Suggestions for future research}

The literature provided evidence of linear relationships between all predictor variables and TIs (Coyne \& Ong, 2007; Knudsen et al., 2006; Koyuncu et al., 2006; Leiter et al., 2009; Lingard, 2003; Rothmann \& Joubert, 2007; Saks, 2006; Schaufeli \& Bakker, 2004; Sims, 2007; Wegge et al., 2006), with the exception of work alienation. However, no substantial evidence of a relationship between the predictive model as a whole and TI is provided in $\mathrm{I} / \mathrm{O}$ psychological literature and needs to be addressed in future longitudinal research projects. In this study, roughly $40 \%$ of the variance in TI remains unexplained, which begs the question as to what other variables should be included in this model? Future research can explore the possibility of an extended model that better explains TI.

Future researchers are urged to match greater numbers of predictive variables when attempting to explain organisational attitudes and behaviour (such as TIs). This will afford other researchers and HR practitioners the luxury of having access to more comprehensive and pragmatic predictive models. It is also 
strongly suggested that the contributing effects of biographical and demographical variables be tested, seeing as very little literature is currently available on the interaction between these variables and the predictive model of TI. The I/O psychological meaning of the construct work alienation can also be explored in more detail (cf. Roodt, 2004a). A complete absence of research on the link between work alienation and TIs exists, even though this study has established a highly significant, positive link between these variables. This relationship needs to be further investigated in future research projects related to withdrawal behaviours and voluntary employee turnover.

\section{Possible limitations of the study}

A first limitation of this study is its cross-sectional field survey design, which hinders the credibility of its causal relationships. Longitudinal designs are usually preferred over cross-sectional designs for the establishment of causal relationships. A second limitation is, as Mouton (2001) also pointed out, the fact that a SDA was performed. Possible data collection errors could not be controlled by the authors and the study was restricted to the original research objectives. A third limitation is the specific focus on an ICT sector sample group. Although the sample size is large $(n=2429)$ and heterogeneous in respect of gender, race, age, marital status, education and job levels, generalising the results to the population outside the ICT sector should be done with caution. A fourth limitation is the exclusive use of self-report measures as data collection tools. A certain amount of social desirability, impression management and random responding are expected in self-report measures.

\section{Conclusion}

Firstly, the main objective of the study was to test the predictive model of the WE-BO continuum and the related concepts OCB and $\mathrm{AL}$, to $\mathrm{TI}$ on a sample of a large ICT sector company. The predictive model of TI was indeed substantiated by the data as well as other predictive relationships with TI. WE and OCB were negatively related to $\mathrm{TI}$ and $\mathrm{BO}$ and $\mathrm{AL}$ were positively related to TI. Secondly, third-variable relationships were also tested for in the prediction of TI. BO was established as a partial mediator in the WE-TI relationship.

\section{ACKNOWLEDGEMENTS}

- The authors would like to thank Roslyn de Braine and Chris Bothma for their kindness in sharing the use of their dataset to conduct the SDA for this study.

- Financial support from the South Africa Netherlands Research Programme on Alternatives in Development (SANPAD) for conducting this research is hereby acknowledged. Conclusions drawn or opinions expressed in this article are those of the authors, and do not necessarily reflect the views of SANPAD.

\section{REFERENCES}

Anderson, J.M. (2008). Depression, stress, and work: How occupation can affect mental health. Journal of Controversial Medical Claims, 15, 6-15.

Baba, V.V., Galperin, B.L., \& Lituchy, T. R. (1999). Occupational mental health: A study of work-related depression among nurses in the Caribbean. International Journal of Nursing Studies, 36, 163-169.

Bakker, A.B., \& Demerouti, E. (2007). The job demands-resources model: State of the art. Journal of Managerial Psychology, 22, 309-328.

Bakker, A.B., Demerouti, E., \& Schaufeli, W.B. (2003). Dual processes at work in call centre: An application of the job demands-resources model. European Journal of Work and Organizational Psychology, 12, 393-417.
Bakker, A.B., Demerouti, E., \& Verbreke, W. (2004). Using the job demands-resources model to predict burnout and performance. Human Resource Management, 43, 83-104.

Bakker, A.B., Schaufeli, W.B., Leiter, M.P., \& Taris, T.W. (2008). Work engagement: An emerging concept in occupational health psychology. Work \& Stress, 22, 187-200.

Banai, M., Reisel, W.D., \& Probst, T.M. (2004). A managerial and personal control model: Predictions of work alienation and organizational commitment in Hungary. Journal of International Management, 10, 375-392.

Barlow, D.H., \& Durand, V.M. (2005). Abnormal psychology: An integrative approach. Belmont: Thomson Wadsworth.

Baron, R.M., \& Kenny, D.A. (1986). The moderator-mediator variable distinction in social psychology research: Conceptual, strategic, and statistical considerations. Journal of Personality and Social Psychology, 51, 1173-1182.

Bluedorn, A.C. (1982). Managing turnover strategically. Business Horizons, March-April, 6-12.

Byrne, B.M. (1993). The Maslach Burnout Inventory: Testing for factorial validity and invariance across elementary, intermediate and secondary teachers. Journal of Occupational and Organizational Psychology, 66, 197-212.

Cherniss, C. (1980). Professional burnout in human service organizations. New York: Praeger.

Coyne, I., \& Ong, T. (2007). Organizational citizenship behaviour and turnover intention: A cross-cultural study. International Journal of Human Resources Management, 18, 1085-1097.

Cramer, D. (2003). Advanced quantitative data analysis. New York: Open University Press.

Cropanzano, R., Rupp, D.E., \& Byrne, Z.S. (2003). The relationship of emotional exhaustion to job performance ratings and organizational citizenship behaviour. Journal of Applied Psychology, 88, 160-169.

Dean, D.G. (1961). Alienation: Its meaning and measurement. American Sociological Review, 26, 753-758.

De Lara, P.Z.M., \& Rodríquez, T.F.E. (2007). Organizational anomie as moderator of the relationship between an unfavourable attitudinal environment and citizenship behaviour (OCB): An empirical study among university administration and services personnel. Personnel Review, 36, 843-866.

Demerouti, E., Bakker, A.B., Nachreiner, F., \& Schaufeli, W.B. (2001). The job demands-resources model of burnout. Journal of Applied Psychology, 86, 499-512.

Denton, D.A., Newton, J.T., \& Bower, E.J. (2008). Occupational burnout and work engagement: A national survey of dentists in the United Kingdom. British Dental Journal, 205, $1-8$.

Dreher, G.F., \& Dougherty, T.W. (1980). Turnover and competition for expected job openings: An exploratory analysis. Academy of Management Journal, 23, 766-772.

Fay, D., \& Sonnentag, S. (2002). Rethinking the effects of stressors: A longitudinal study on personal initiative. Journal of Occupational Health Psychology, 7, 221-234.

Fogarty, T.J., Singh, J., Rhoads, G.K., \& Moore, R.K. (2000). Antecedents and consequences of burnout in accounting: Beyond the role stress model. Behavioral Research in Accounting, 12, 31-67.

Frazier, P.A., Tix, A.P., \& Barron, K.E. (2004). Testing moderator and mediator effects in counseling psychology. Journal of Counseling Psychology, 51, 115-134.

Fredrickson, B.L. (2001). The role of positive psychology: The broaden-and-build theory of positive emotions. American Psychologist, 56, 218-226.

Fredrickson, B.L. (2003). Positive emotions and upward spirals in organizations. In K.S. Cameron, J.E. Dutton \& R.E. Quinn (Eds.), Positive organizational scholarship (pp. 163-175). San Francisco: Berrett-Koehler.

Geurts, S., Schaufeli, W. B. \& Rutte, C. G. (1999). Absenteeism, turnover intention and inequity in the employment relationship. Work E Stress, 13, 253-267.

González-Romá, V., Schaufeli, W.B., Bakker, A.B., \& Lloret, S. (2006). Burnout and work engagement: Independent factors or opposite poles? Journal of Vocational Behavior, 68, 165174 
Griffeth, R.W., Hom, P.W., \& Gaertner, S. (2000). A meta-analysis of antecedents and correlations of employee turnover: Update, moderator tests, and research implications for the next millennium. Journal of Management, 26, 463488.

Hakanen, J.J., Bakker, A.B., \& Schaufeli, W.B. (2006). Burnout and work engagement among teachers. Journal of School Psychology, 43, 495-513.

Hakanen, J.J., Schaufeli, W.B., \& Ahola, K. (2008). The JobDemands-Resources Model: A three-year cross-lagged study of burnout, depression, commitment, and work engagement. Work E Stress, 22, 224-241.

Hallberg, U.E., Johansson, G., \& Schaufeli, W.B. (2007). Type A behaviour and work situation: Associations with burnout and work engagement. Scandinavian Journal of Psychology, 48 , 135-142.

Hemdi, M.A., \& Nasurdin, A.M. (2008). Investigating the influence of organizational justice on hotel employees' organizational citizenship behaviour intentions and turnover intentions. Journal of Human Resources in Hospitality $\mathcal{E}$ Tourism, 7, 1-23.

Herselman, S. (2004). Cultural diversity, group formation and alienation as constraints on employee interaction in a wholesale company. Anthropology Southern Africa, 27, 122128.

Hobfoll, S.E. (2001). The influence of culture, community, and the nested-self in the stress process: Advancing conservation of resources theory. Applied Psychology: An International Review, 50, 337-421.

Huang, I., Chaung, C.J., \& Lin, H. (2003). The role of burnout in the relationship between perceptions of organizational politics and turnover intentions. Public Personnel Management, 32, 519-531.

Huhtala, H., \& Parzefall, M. (2007). A review of employee wellbeing and innovativeness: An opportunity for mutual benefit. Creativity and Innovative Management, 16, 229306.

Jackson, L.T.B., Rothmann, S., \& Van der Vijver, F.J.R. (2006) A model of work-related wellbeing for educators in South Africa. Stress and Health, 22, 263-274.

Jacobs, E.J. (2005). The development of a predictive model of turnover intentions of professional nurses. Unpublished doctoral thesis. Johannesburg: University of Johannesburg

Joubert, E., Crafford, A., \& Schepers, J.M. (2004). The construction of a normative instrument measuring organisational citizenship. SA Journal of Industrial Psychology, 30, 1-10.

Kaiser, H.F. (1970). A second generation little jiffy. Psychometrika, 35, 401-415.

Kanungo, R.N. (1979). The concepts of alienation and involvement revisited. Psychological Bulletin, 86, 119-138.

Karger, H.J. (1981). Burnout as alienation. Social Service Review, 55, 270-283.

Knudsen, H.K., Ducharme, L.J., \& Roman, P.M. (2006). Counselor emotional exhaustion and turnover intention in therapeutic communities. Journal of Substance Abuse Treatment, 31, 173180.

Kop, N., Euwema, M., \& Schaufeli, W.B. (1999). Burnout, job stress and violent behaviour among Dutch police officers. Work $\mathcal{E}$ Stress, 13, 326-340.

Korman, A.K., Wittig-berman, U., \& Lang, D. (1981). Career success and personal failure: Alienation in professionals and managers. Academy of Management Journal, 24, 342-360.

Kotzé, K., \& Roodt, G. (2005). Factors that affect the retention of managerial and specialist staff: An exploratory study of an employee commitment model. SA Journal of Human Resource Management, 3, 48-55.

Koyuncu, M., Burke, R.J., \& Fiksenbaum, L. (2006). Work engagement among women managers and professionals in a Turkish bank. Equal Opportunities International, 25, 299310.

Lee, R.T., \& Ashforth, B.E. (1993). A future examination of managerial burnout: Towards an integrated model. Journal of Organizational Behavior, 14, 3-20.
Lee, T.W., Mitchell, T.R., Holtom, B.C., McDaniel, L.S. \& Hill, J.W. (1999). The unfolding model of voluntary turnover: A replication and extension. Academy of Management Journal, 42, 450-462.

Leiter, M.P., Jackson, N.J., \& Shaughnessy, K. (2009). Contrasting burnout, turnover intention, control, value congruence and knowledge sharing between Baby Boomers and Generations X. Journal of Nursing Management, 17, 100-109.

Lingard, H. (2003). The impact of individual and job characteristic on 'burnout' among civil engineers in Australia and the implications for employee turnover. Construction Management and Economics, 21, 69-80.

Marais, C., Mostert, K., \& Rothmann, S. (2009). The psychometrical properties of translated versions of the Maslach Burnout Inventory - General Survey. SA Journal of Industrial Psychology, 35, 1-8.

Martin, A., \& Roodt, G. (2007). Employee perceptions of organisational commitment, job satisfaction and turnover intentions in a post-merger institution. Unpublished masters dissertation, Johannesburg: University of Johannesburg.

Maslach, C., \& Jackson, S.E. (1981). The measurement of experienced burnout. Journal of Occupational Behaviour, 2, 99-113.

Maslach, C., Jackson, S.E., \& Leiter, M.P. (1997). Maslach Burnout Inventory. (3rd edn.). In C.P. Zalaquett \& R.J. Wood, Evaluating stress: A book of resources (pp. 191-218). London: The Scarecrow Press.

Maslach, C., Schaufeli, W.B., \& Leiter, M.P. (2001). Job burnout. Annual Review of Psychology, 52, 397-422.

Mauno, S., Kinnunen, U., \& Ruokolainen, M. (2007). Job demands and resources as antecedents of work engagement: A longitudinal study. Journal of Vocational Behavior, 70, 149171.

Mobley, W.H. (1982). Some unanswered questions in turnover and withdrawal research. Academy of Management Review, 7, 111-116.

Moliner, C., Martínez-Tur, V., Ramos, J., Peiro, J.M., \& Cropanzano, R. (2008). Organizational justice and extra-role customer service: The mediating role of well-being at work. European Journal of Work and Organizational Psychology, 17, 327-348.

Mouton, J. (2001). How to succeed in your master's $\mathcal{E}$ doctoral studies: A South African guide and resource book. Pretoria: Van Schaik Publishers.

Nunnally, J.C. (1978). Psychometric theory. (2nd edn.). New York: McGraw-Hill.

Organ, D.W. (1988). A restatement of the satisfactionperformance hypothesis. Journal of Management, 14, 547-557.

Organ, D.W. (1997). Organizational citizenship behaviour: It's construct clean-up time. Human Performance, 10, 85-97.

Organ, D.W., \& Paine, J.B. (1999). A new kind of performance for industrial and organizational psychology: Recent contributions to the study of organizational citizenship behavior. In C.L. Cooper \& I.T. Robertson (Eds.), International review of industrial and organizational psychology (Vol. 14; pp. 337-368). West Sussex: Wiley.

Pallant, J. (2007). SPSS survival manual: A step-by-step guide to data analysis using SPSS version 15. (3rd edn.). New York: Open University Press

Pietersen, H.J. (1989). An epistemological view of industrial/ organisational psychology: Some perspectives and implications for future knowledge development. SA Journal of Industrial Psychology, 19, 101-108.

Podsakoff, P.M., MacKenzie, S.B., \& Bommer, W.H. (1996) Transformational leader behaviours and substitutes for leaders as determinants of employee satisfaction, commitment, trust, and organizational citizenship behaviours. Journal of Management, 22, 259-298.

Podsakoff, P.M., MacKenzie, S.B., Paine, J.B., \& Bachrach, D.G. (2000). Organizational citizenship behaviors: A critical review of the theoretical and empirical literature and suggestions for future research. Journal of Management, 26, 513-563. 
Ravichandran, S., \& Gilmore, S.A. (2007). Formation of organizational citizenship behaviours in students employed in university dining services: Impact of manger and co-worker behaviours. Journal of Foodservice Business Research, 10, 19-50.

Ready, D.A., Hill, L.A. \& Conger, J.A. (2008). Winning the race for talent in emerging markets. Harvard Business Review, November, 63-70.

Roodt, G. (2004a). Concept redundancy and contamination in employee commitment research: Current problems and future directions. SA Journal of Industrial Psychology, 30, $82-90$.

Roodt, G. (2004b). Turnover intentions. Unpublished document, Johannesburg: University of Johannesburg.

Roodt, G., \& Bothma, F.C. (1997). Die koste van vrywillige, beheerbare arbeidsomset. SA Journal of Industrial Psychology, $23,26-30$.

Rothmann, S., \& Joubert, J.H.M. (2007). Job demands, job resources, burnout and work engagement of managers at a platinum mine in the North West Province. South African Journal of Business Management, 38, 49-61.

Saks, A.M. (2006). Antecedents and consequences of employee engagement. Journal of Managerial Psychology, 21, 600-619.

Salanova, M., Bakker, A.B., \& Llorens, S. (2006). Flow at work: Evidence for an upward spiral of personal and organizational resources. Journal of Happiness Studies, 7, $1-22$.

Schurink, E.M. (1998). Deciding on the use of a quantitative research approach. In A.S. Vos (Ed.), Research at grass roots (239-251). Pretoria: Van Schaik,

Schaufeli, W.B. (2009). Test-forms. Retrieved April 20, 2009, from http://www.schaufeli.com/

Schaufeli, W.B., \& Bakker, A.B. (2003). UWES manual. Utrecht: Occupational Health Psychology Unit, Utrecht University.

Schaufeli, W.B., \& Bakker, A.B. (2004). Job demands, job resources, and their relationship with burnout and engagement: A multi-study sample. Journal of Organizational Behavior, 25, 293-315.

Schaufeli, W.B., Bakker, A.B., Hoogduin, K., Schaap, C., \& Kladler, A. (2001). On the clinical validity of the Maslach Burnout Inventory and the Burnout Measure. Psychology and Health, 16, 565-582.

Schaufeli, W.B., \& Buunk, B.P. (2003). Burnout: an overview of 25 years of research and theorizing. In M.J. Schabracq, J.A.M. Winnubst \& C.L. Cooper (Eds.), Handbook of work and health psychology (pp. 383-425). Chichester: Wiley.

Schaufeli, W.B. \& Enzmann, D. (1998). The burnout companion to study and practice: A clinical analysis. London: Taylor and Francis.

Schaufeli, W.B., Salanova, M., González-romá, V., \& Bakker, A.B. (2002). The measurement of engagement and burnout: A two sample confirmatory factor analytic approach. Journal of Happiness Studies, 3, 71-92.
Schaufeli, W.B. \& Van Dierendonck, D. (1993). The construct validity of two burnout measures. Journal of Organizational Behavior, 14, 631-647.

Schutte, N., Toppinen, S., Kalimo, R., \& Schaufeli, W. B. (2000). The factorial validity of the Maslach Burnout InventoryGeneral Survey (MBI-GS) across occupational groups and nations. Journal of Occupational and Organizational Psychology, $73,53-66$.

Shepard, J.M. (1972). Alienation as a process: Work as a case in point. The Sociological Quarterly, 13, 161-173.

Shimazu, A., Schaufeli, W.B., Kosugi, S., Suzuki, A., Nashiwa, H., Kato, A., Sakamoto, M., Irimajiri, H., Amano, S., Hirohata, K., Goto, R., \& Kitaoka-Higashiguchi, K. (2008). Work engagement in Japan: Validation of the Japanese version of the Utrecht Work Engagement Scale. Applied Psychology: An International Review, 57, 510-523.

Simpson, M.R. (2008). Engagement at work: A review of the literature. International Journal of Nursing Studies, 45, 1-13.

Sims, W.J. (2007). Antecedents of labor turnover in Australian Alphine Resorts. Journal of Human Resources in Hospitality $\mathcal{E}$ Tourism, 6, 1-26.

Smith, C.A., Organ, D.W. \& Near, J.P. (1983). Organizational citizenship behavior: Its nature and antecedents. Journal of Applied Psychology, 68, 653-663.

Sonnentag, S. (2003). Recovery, work engagement, and proactive behavior: A new look at the interface between nonwork and work. Journal of Applied Psychology, 88, 518528.

Storm, K., \& Rothmann, S. (2003). A psychometric analysis of the Utrecht Work Engagement Scale in the South African Police Service. SA Journal of Industrial Psychology, 29, 6270.

Tekleab, A.G., Takeuchi, R., \& Taylor, M.S. (2005). Extending the chain of relationships among organizational justice, social exchange, and employee reactions: The role of contract violations. Academy of Management Journal, 48, $146-157$.

Tett, R.P., \& Meyer, J.P. (1993). Job satisfaction, organizational commitment, turnover intention, and turnover: Path analyses based on meta-analytic findings. Personnel Psychology,

Van Dyne, L., \& LePine, J.A. (1998). Helping and voice extra-role behaviours: Evidence of construct and predictive validity. Academy of Management Journal, 42, 108-119.

Vanheule, S., Rosseel, Y., \& Vlerick, P. (2007). The factorial validity and measurement invariance of the Maslach Burnout Inventory for human services. Stress and Health, 23, 87-91.

Wegge, J., van Dick, R., Fisher, G.K., Wecking, C., \& Moltzen, K. (2006). Work motivation, organizational identification, and well-being in call centre work. Work \& Stress, 20, 60-83.

Zimmerman, R.D. (2008). Understanding the impact of personality traits on individuals' turnover decisions: A meta-analytic path model. Personnel Psychology, 61, 309348 